\title{
Analysis Using High-Precision Airborne LiDAR Data to Survey Potential Collapse Geological Hazards
}

\author{
Jinxing She $\mathbb{D}^{1,2}$, Awei Mabi, ${ }^{3}$ Zhongming Liu $\mathbb{D}^{3},{ }^{3}$ Mingqiang Sheng, ${ }^{3}$ Xiujun Dong, \\ Fei Liu, ${ }^{2}$ and Shiyang Wang ${ }^{4}$ \\ ${ }^{1}$ Chengdu University of Technology, Chengdu 610059, China \\ ${ }^{2}$ Technology Service Center of Surveying and Mapping, Sichuan Bureau of Surveying, Mapping and Geoinformation, \\ Chengdu 615000, China \\ ${ }^{3}$ Nanchang Institute of Science and Technology, Nanchang 330000, China \\ ${ }^{4} 32023$ Troops, Dalian 116023, China \\ Correspondence should be addressed to Zhongming Liu; 781637124@qq.com
}

Received 22 April 2021; Revised 2 September 2021; Accepted 11 September 2021; Published 12 October 2021

Academic Editor: Edén Bojórquez

Copyright (c) 2021 Jinxing She et al. This is an open access article distributed under the Creative Commons Attribution License, which permits unrestricted use, distribution, and reproduction in any medium, provided the original work is properly cited.

\begin{abstract}
On August 8, 2017, an earthquake of magnitude 7.0 on the Richter scale occurred in Jiuzhaigou, Sichuan, causing significant damage to both life and property. Traditional geological hazard investigation is difficult in Jiuzhaigou because of the high altitude, the high-altitude canyons, and the vegetation-covered seismic areas. This study explores the technical advantages of using airborne LiDAR technology to penetrate vegetation and gather information directly from the surface, rapidly acquiring airborne 3D point cloud data in difficult areas. Through the preprocessing of data, the high-precision digital terrain and landform results were obtained. Comparative research found that the DEM obtained by high-precision airborne LiDAR technology has significant advantages in terms of the accuracy, details, and microgeomorphology of the data collected. The results can be directly used in the early identification of disasters, such as during the initial collapse or for disaster management. Studies have shown that airborne LiDAR has the technical advantage of penetrating vegetation to the surface and can, therefore, be used to guide the early identification and management of geological disasters in similar areas in the future.
\end{abstract}

\section{Introduction}

Rockfall hazards are phenomena that commonly occur in mountainous regions [1-3]. During a rockfall, a solid body composed of rock and soil moves under the action of gravity, rolling, bouncing, and falling down a slope. Lithological conditions, geological formations, topography, earthquakes, precipitation, and improper engineering are all important factors that trigger rockfall $[4,5]$. In many countries, rockfall hazards generate significant annual losses to property and human life compared to other types of natural hazards; more attention has therefore been paid to this type of hazard [6-10], especially in areas that lie along mountain roads and some railways, where rockfall hazards are a district danger.

In recent years, extreme weather has become more frequent, engineering activities have continued to intensify, and the impact of strong earthquakes has continued to affect mountainous regions, causing abrupt and unexpected geological disasters in these regions [11]. Jiuzhaigou in Northwest Sichuan is characterized by mountains of high altitude and has endured a series of strong earthquakes, such as the Wenchuan and Lushan earthquakes which shattered a considerable number of high-altitude rocks and cracked much of the slopes on the mountainside. Fractures that subsequently developed in these rocks led to a substantial increase in the amount of material present that was likely to lead to hazards. The Mw 7.0 Jiuzhaigou Earthquake that occurred on 8 August 2017 led to approximately 300 rockfall events, causing 25 deaths in 8 counties, with 525 injured and 6 missing. A total of 176492 people (including tourists) were affected to varying degrees, 73671 residential properties were damaged, and the destruction covered a total area of $18295 \mathrm{~km}^{2}[12,13]$. 
Faced with the severe challenge from natural disasters, humanity needs to reflect on the impact that the current lifestyle has on the environment $[14,15]$. Significant amounts of effort have been focused over the last twenty years on predicting the mechanisms that trigger rockfall hazards, including the spatial and temporal distributions and the consequences [16-21].

As a result, several techniques that can be used for mapping rockfall susceptibility, hazard, and risk have been developed and applied in different geographic areas [22-24].

Airborne laser radar technology and the first 3D rolling stone/rockfall process model that has been integrated with the GIS environment were mainly used in this study for identification and evaluation, to improve rockfall hazard studies for Jiuzhaigou environmental management and to improve rockfall susceptibility mapping and analyses. Remote sensing geological disaster interpretation technology, airborne laser radar digital terrain analysis technology, GIS data processing technology, and image morphology analysis were combined with field investigation to evaluate the most serious threats from rockfall and to identify the source area of rockfalls. Combining the quantitative evaluation model of rockfall frequency, speed, and height with a quantitative analysis of the physical rocks that have fallen, the realization of the rolling stones/rockfall three-dimensional physical deterministic process model and probability statistics model are combined to improve predictions of the risk of disaster in the Jiuzhaigou National Park.

\section{Study Area}

Jiuzhaigou is located between the Qinghai-Tibet plateau and the Sichuan basin in a mountain transition zone $\left(100^{\circ}\right.$, $30-104^{\circ} 27^{\prime}$ north and latitude $30^{\circ}, 34-35^{\circ} 19^{\prime}$ ) and is a world natural heritage site, national key scenic area, national 5 A-class tourist scenic area, and a national geological park. The mouth of the Jiuzhaigou River is only $2000 \mathrm{~m}$ above sea level, while the central peaks in this region are at heights above $4000 \mathrm{~m}$ and the southern margin is over $4500 \mathrm{~m}$. Original forest covers $80 \%$ of the valley [25-28].

The 2017 earthquake not only caused casualties and property loss, but it also led to geological disasters and problems in the ecological balance that still affect some areas such as the famous Panda Sea, the Five Flower Lake, some waterfalls, and other parts of the landscape that suffered serious damage. The vertical topography of Jiuzhaigou changed significantly, and natural disasters and geological hazards such as landslides, rockfalls, and wide-scale flows of debris threatened the entire $651 \mathrm{~km}^{2}$ of the National Park of Jiuzhaigou, with the formation of more than 30 gullies containing flows of debris.

Geological disasters have tended to be dominated by debris flow since 1980, with 10 major mudslides occurring from 1980 to 1985, and another large mudslide in 2003 $[29,30]$. The earthquake on 12 May 2008 in Wenchuan had a significant impact, causing many secondary geological disasters, and serious safety hazards have remained in several areas. A comprehensive geological survey of Jiuzhaigou National Park was carried out in early 2010, and more than 50 locations were identified at which geological hazards are likely to happen $[31,32]$. Earthquakes that reach 8.8 on the
Richter scale are therefore likely to aggravate the risk of geological disaster in Jiuzhaigou, constituting a threat to the ecological environment, landscape, roads, residential areas, river systems, and the safety of tourists that severely restricts both the tourism and the development of the economy in Jiuzhaigou (Figure 1).

\section{Materials and Methods}

Figure 2 is a schematic diagram of the proposed methods. It consists of three major components: (i) the acquisition of LiDAR data and preprocessing, (ii) the identification of the rockfall source area via digital terrain analysis using techniques such as morphometry, topography, remote sensing geology, 3D GIS technology, and human-computer interactive interpretation, and (iii) the analysis and assessment of rockfall hazards.

\subsection{Spatial Modeling and Advantages of LiDAR Technology.} RockFall Analyst is the first 3D rolling stone rockfall process model that is fully integrated with the GIS environment, combining the rolling stone/rockfall 3D physical deterministic process model with a statistical probability model to improve the accuracy of disaster risk analysis. Two major steps are utilized by Rockfall Analyst. First, a 3D dynamic model uses physics to calculate and predict the $3 \mathrm{D}$ trajectory of rolling stones and falling rocks, accompanied by information concerning the velocity, the dynamic processes that occur during flight through the air, collision, rebound, rolling, and sliding. Secondly, the rolling stone and rockfall disaster space grid analysis model is initiated, converting the information about the falling rocks and the velocity that was obtained in vector format during the first step into a grid format that can be used to better relay spatial information concerning the elements of the disaster. Statistical software, the adjacent domain analysis technique, and methods that estimate the surface smoothness are then utilized to predict the spatial distribution of the various elements of rockfall, including the frequency, potential energy, and the three main elements of kinetic energy.

Airborne LiDAR includes a position measurement system, an attitude measurement system, a 3D laser scanner (point cloud access), equipment for gathering images such as $3 \mathrm{D}$ laser scanner active laser beam, by which precise information about the target such as distance, slope, roughness, and reflectance can be obtained from the returning laser pulse, and a digital camera, which is used to acquire the digital image of the target. Subsequent processing of the information gathered with airborne radar can generate $3 \mathrm{D}$ laser point clouds with true color (or ground reflection intensity). Compared to traditional photogrammetric techniques, airborne LiDAR not only provides high-resolution, high-precision two-dimensional images of the topography and landform but also uses multiple echo techniques that can penetrate ground vegetation, effectively removing the influence of surface vegetation via a filtering algorithm to obtain accurate data concerning ground elevation. As a result, LiDAR technology is usually used in situations where high mountains are covered by substantial 


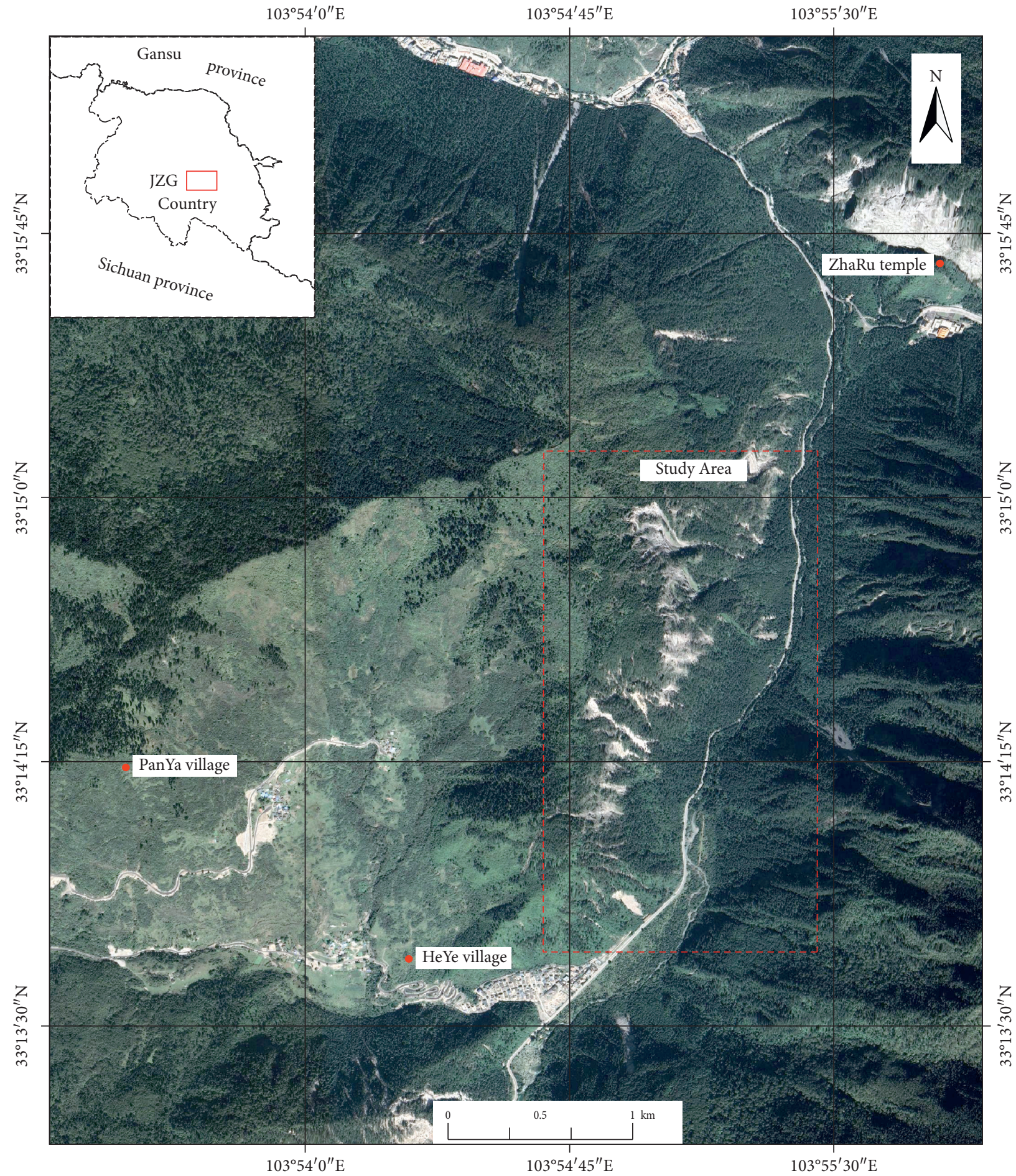

FIgURE 1: The map of study area. The red dotted box is the scope of the study area, where vegetation damage caused by the earthquake caused a collapse, threatening the road directly below.

amounts of vegetation, effectively eliminating the effects produced by the presence of vegetation and providing a true picture of the ground. LiDAR is therefore useful for identifying potential geological hazards in areas with substantial amounts of the mountain vegetation, especially for identifying ancient landslides (Figure 3), or areas where earthquakes have led to the shattering of rocks and caused minor rockfalls without accompanying landslides.
3.2. LiDAR Capturing and Processing. Measurement using remote sensing geological airborne LiDAR technology has been ongoing in Jiuzhaigou since September 2017. The first phase of the data was acquired during September 2017 with Mi-171 helicopters carrying the Leica ALS80 airborne LiDAR system flying at an altitude of $1400 \mathrm{~m}$ at $150 \mathrm{~km} / \mathrm{h}$, using a laser pulse frequency of $100 \mathrm{kHz}$, a point cloud density of 20 points/square meters, and an image resolution 


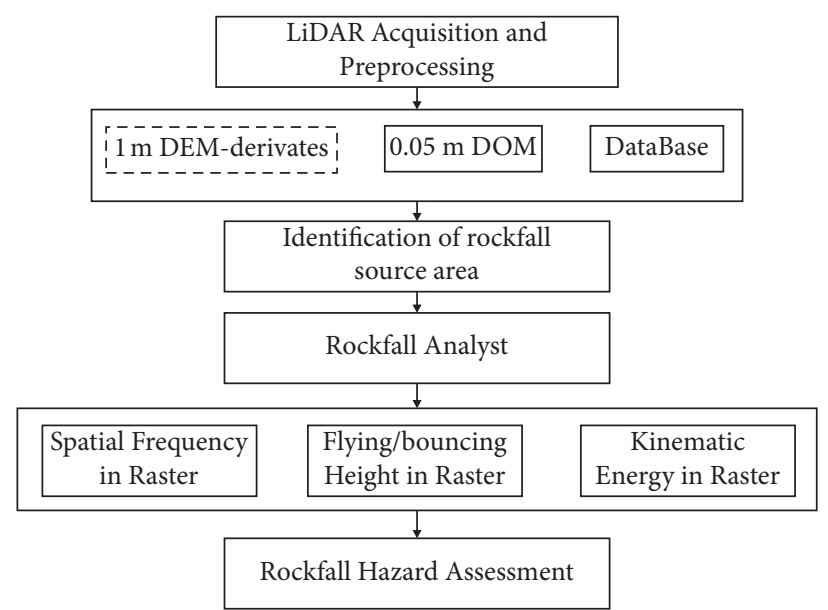

FIGURE 2: Rockfall hazard assessment workflow using airborne LiDAR and Rockfall Analyst.

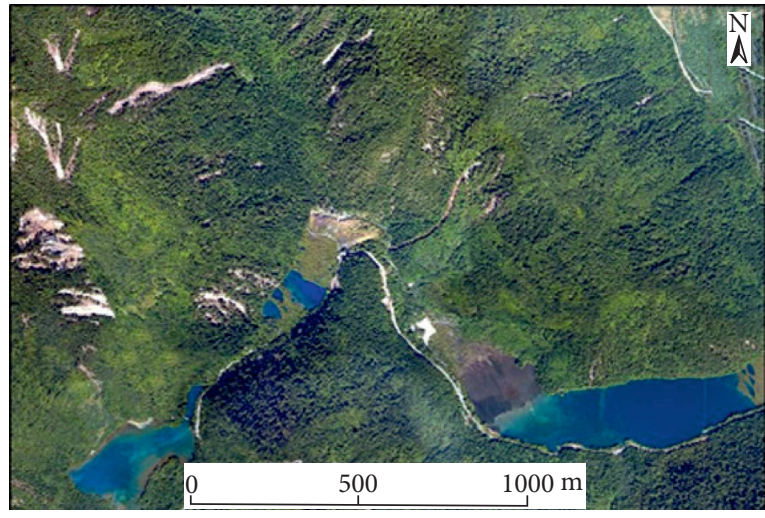

(a)

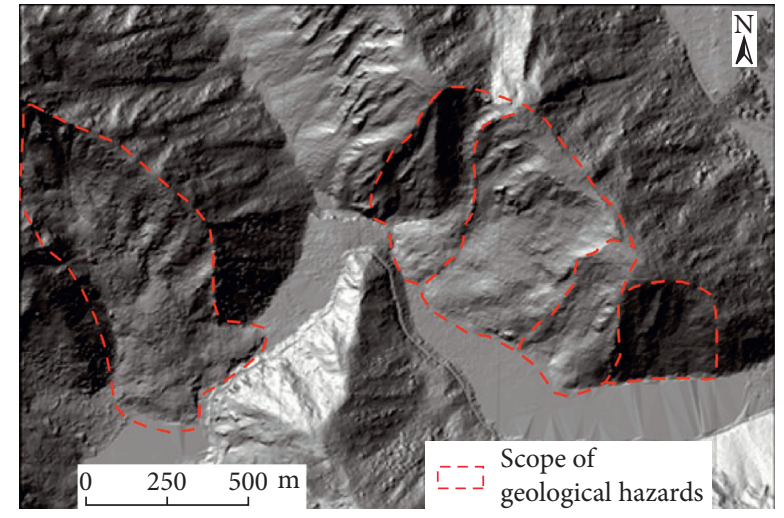

(b)

FIgURe 3: Comparison of an optical image and airborne LiDAR data. (a) Orthophoto map for disaster interpretation. (b) Shadow map of the same mountains in which vegetation has been filtered out based on laser point cloud data.

of $0.05 \mathrm{~m}$. Through LiDAR strip adjustment, point cloud denoising, filtering, classifying, and the construction of a triangulated irregular network (TIN), a digital elevation model (DEM) with a horizontal resolution of $1 \mathrm{~m}$ and a vertical accuracy of $\pm 20 \mathrm{~cm}$ was generated from the highresolution-based ground LiDAR point data. A coarser DEM with a resolution of $30 \mathrm{~m}$ (30 m DEM) was provided for comparison by the Geospatial Data Cloud site, Computer Network Information Center, Chinese Academy of Sciences (http://www-.gscloud.cn). Comparison found that the highresolution DEM was capable of providing more detailed geological hazard prediction from information concerning the characteristics of precursors such as physiognomy, gullies, steep cliff scarps, the presence of clastic rocks, and other associated information (Figure 4).

3.3. Fine Processing Based on the Geological Hazard Remote Sensing Survey. The accuracy of recognizing and evaluating rockfall hazards is directly proportional to the mathematical accuracy, point cloud density, and quality of the LiDAR data. In the process of denoising and filtering point clouds, classification, modeling, and the production of a DEM, only one original laser point per $\mathrm{m}^{2}$ is provided with traditional

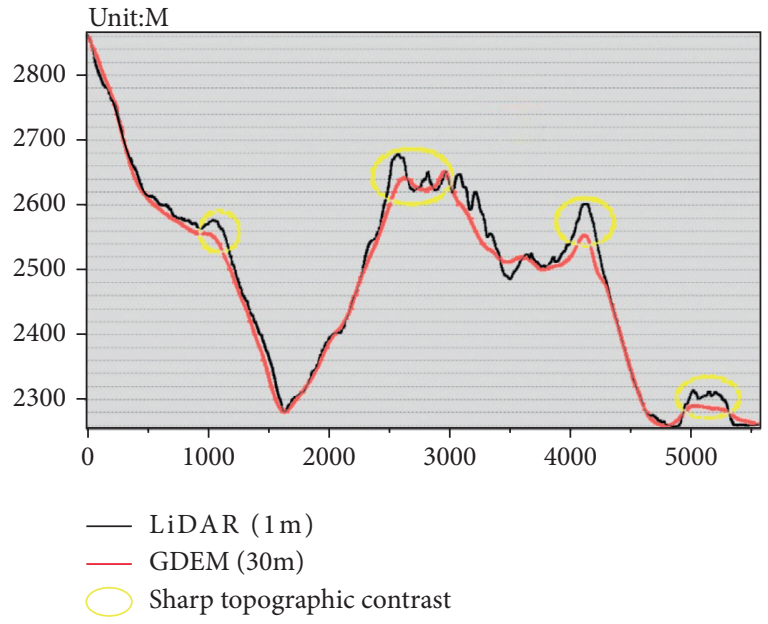

Figure 4: Comparison of the $1 \mathrm{~m}$ resolution DEM from LiDAR and the $30 \mathrm{~m}$ AsterGDEM DEM terrain profile data.

mapping in accordance with conventional criteria such as a $1: 2000$ scale, and only four original laser points are produced on a scale of $1: 1000$. Although this can meet the requirements for surveying and producing topographic 
maps, it is far from adequate for the interpretation of refined geological hazards. The original point cloud was filtered to remove the true surface point clouds retained by vegetation, which could not meet the requirements for the extraction of information pertaining to disaster precursors. On the other hand, if the laser point cloud density is higher, the penetration rate is stronger, and more ground points are obtained through automatic filtering and manual intervention, meaning that topographies can be attained in finer detail, which is more conducive to the extraction of information concerning disaster precursors and the demarcation of the source area of materials for potential rockfall disasters. The classification algorithm based on laser echo frequency, point cloud elevation, and the use of the nadir to extract ground points were, therefore, used in this study. By fully integrating the advantages of the above algorithms, more detailed textures can be obtained for the interpretation of geological hazards. Figures 5(a) and 5(b) show a comparison of the same image before and after improvement.

\subsection{Identification of Rockfall Based on Digital Terrain Analysis} Techniques. The identification of the source area for material that is involved in rockfall disasters is divided into two steps. The first step was to use information concerning 100 known rockfall points that were obtained by the geological survey department from 1998 to 2017 as the dependent variable. The location of the above historical disaster points was identified via superposition of spatial positions, and the potential for further rockfalls was analyzed using highprecision data from airborne LiDAR, identifying new source areas. It was found by statistical analysis that rockfalls that occur in Jiuzhaigou have the following characteristics. Rockfall hazards occur most often in approximately 3000 areas that are close to roads, indicating a close relationship between rockfall and construction. Secondly, there is a rapid upward trend in the probability of rockfall on slopes that are greater than $45^{\circ}$. Figure $6(\mathrm{a})$ presents a 3D interpretation scene of collapse geological hazard potential constructed using $0.5 \mathrm{~m}$ optical remote sensing image data and $1 \mathrm{~m}$ DEM data. Figure 6(b) describes the use of image recognition algorithm to extract the collapse hazard potential range based on $0.5 \mathrm{~m}$ disaster remote sensing image data, based on which postearthquake disaster rapid statistics can be carried out. Figure 6(c) focuses on the collapse geohazard potential hazard detection using the mountain shading technique of digital terrain analysis. As (1) shows [33], disaster potential hazard detection analysis from different viewpoints is realized by changing the solar altitude angle and azimuth angle. Figure 6(d) illustrates the application of slope analysis based on digital terrain technology, which can circle the high side slopes greater than 50 degrees based on slope analysis. Figure 6(e) indicates the terrain compactness analysis, which is also one of the digital terrain analysis techniques, and can provide a reference basis for the identification of the development range of the collapse hazard potential. Figure 6(f) demonstrates the topographic relief analysis, which can analyze the structure of large rock masses and is valuable for defining the scope of landslide hazards.

$$
\begin{aligned}
\text { Hillshade }= & 255.0 *[\operatorname{Cos}(\text { Zenith_rad }) * \operatorname{Cos}(\text { Slope_rad }) \\
& * \operatorname{Sin}(\text { Zenith_rad }) \\
& * \operatorname{Sin}(\text { Slope_rad }) \\
& * \operatorname{Cos}(\text { Azimuth_rad }- \text { Aspect_rad })] .
\end{aligned}
$$

3.5. Modeling Procedure. The simulation and prediction of rockfall hazard can be carried out when the high-risk areas of rockfall hazard are analyzed comprehensively using digital terrain analysis and three-dimensional visualization technology combined with historical data concerning geological disasters. To further examine the effect of topography on rockfall behavior, simulations using DEMs with resolutions of $1 \mathrm{~m}, 12.5 \mathrm{~m}$, and $30 \mathrm{~m}$ were carried out (Figure 7. These simulations included the initial detachment and fall of the rocks and the subsequent bouncing, rolling, sliding, and deposition. Raster images of rockfall spatial frequency, the height of airborne rocks (potential energy), and kinetic energy were provided based on the trajectories and velocities produced by the 3D rockfall simulations. The resolution of each raster image is the same as that of the input DEM. The simulation of the rockfall processes described above using the DEM from the LiDAR survey was repeated using the $30 \mathrm{~m}$ DEM. Using the raster modeling function in Rockfall Analyst, rockfall trajectories were calculated for each grid cell, each of which covered an area of $1 \mathrm{~m}^{2}$. Spatial geostatistical techniques were employed to analyze the trajectories and determine the rockfall spatial frequency for the whole study area. Comparison of the $1 \mathrm{~m}, 12.5 \mathrm{~m}$, and $30 \mathrm{~m}$ DEM data indicated that the simulation of the falling path gradually became more linear and the curvature gradually decreased at lower resolutions, whereas the falling rocks were affected by all variations in topography at a resolution of $1 \mathrm{~m}$, reflecting the linearity of the simulation under the influence of the gravity drop shape process, and verifying the advantages of using high-resolution airborne LiDAR data.

Finally, the potential impact of rockfalls on the Jiuzhaigou area was evaluated using the final rockfall hazard map which takes all available raster layers into account.

\section{Results and Discussion}

4.1. DEMs with Different Resolutions Are Completely Different for Predicting Disasters. Historical rockfall data were combined with digital topography, high-resolution orthophoto images, and $3 \mathrm{D}$ visualization to obtain the source of the rockfall in the study area. As shown in Figure 7, DEM data with different resolutions corresponding to identified potential rockfall points were used to simulate the rockfall and the path taken by these rocks. It was found that the rolling stone path simulated by DEM at an accuracy of $30 \mathrm{~m}$ is almost straight down the slope of the mountain, and the falling speed is particularly fast, reaching $95 \mathrm{~m} / \mathrm{s}$. The influence of topography can be ignored. When DEM precision is increased to $12.5 \mathrm{~m}$, the simulation is better, the rolling 

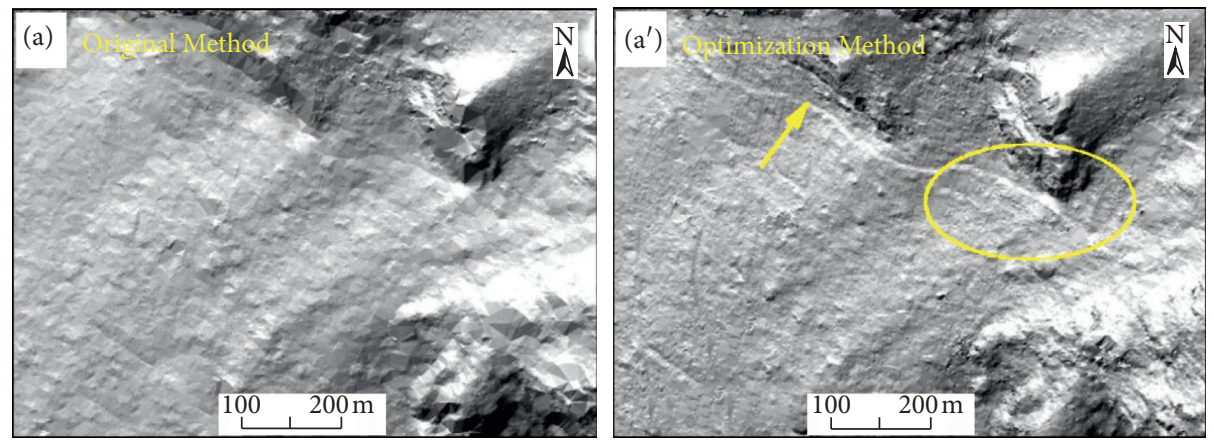

(a)
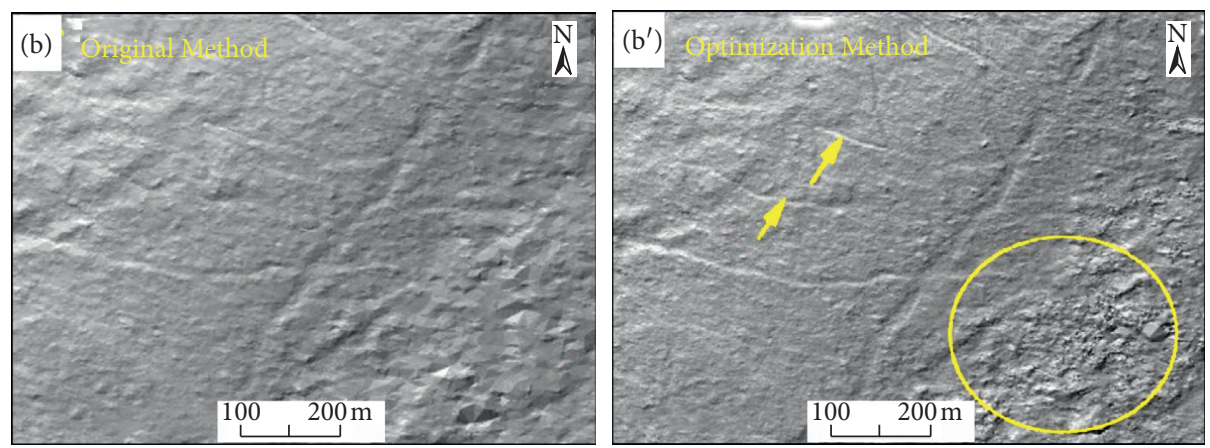

(b)

FiguRE 5: Comparison of the traditional filtering method and the geological filtering method for displaying microgeomorphology: (a, b) the results gained with the traditional filtering algorithm and $\left(\mathrm{a}^{\prime}, \mathrm{b}^{\prime}\right)$ the results of using the optimization filtering algorithm, which produces smaller landforms (steep hills, clastic rocks).

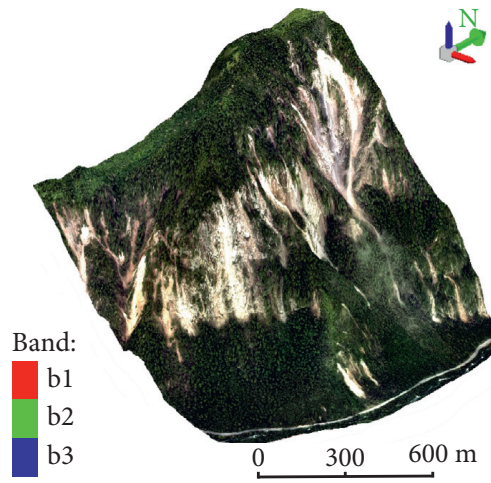

(a)

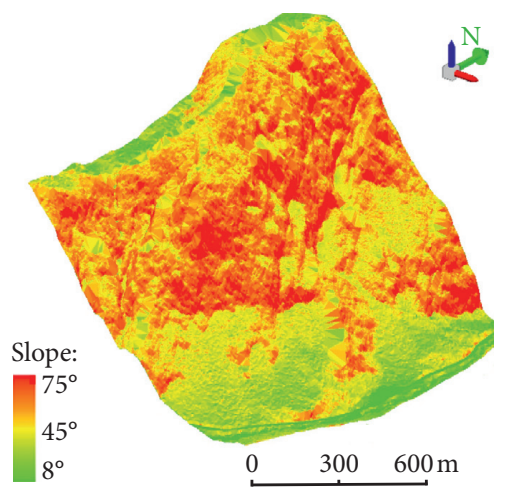

(d)

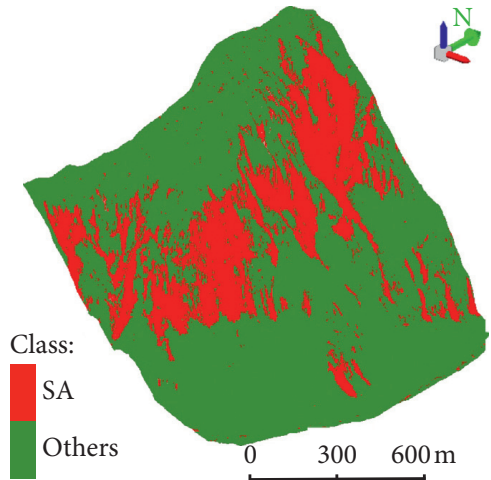

(b)

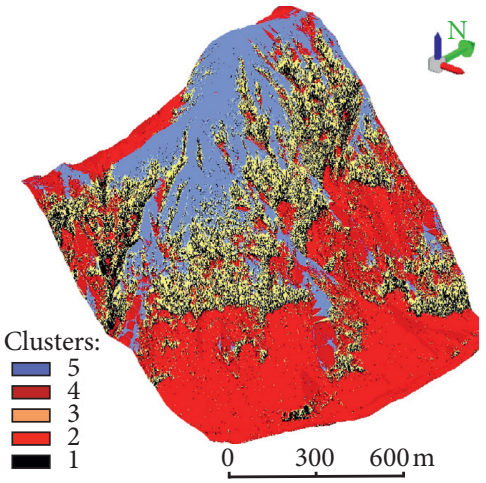

(e)

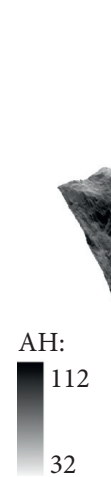

$32 \quad 0 \quad 300 \quad 600 \mathrm{~m}$

(c)

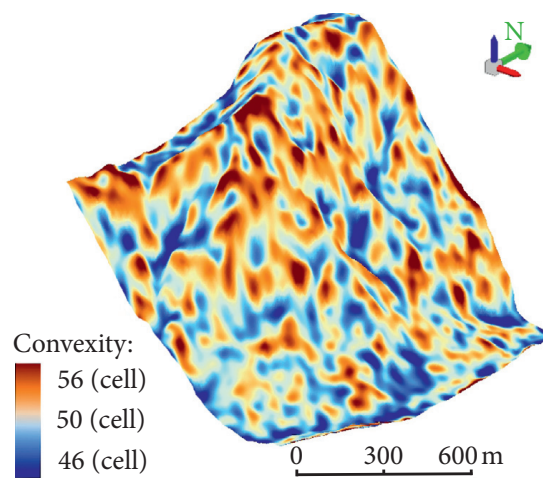

(f)

Figure 6: Identification of the source of the material causing rockfall hazards based on digital terrain analysis technology: (a) 3D visualization technology, (b) neural network classification was used to identify the source area of debris, (c) hill-shading map, (d) slope, (e) terrain clustering, and (f) terrain surface convexity. 


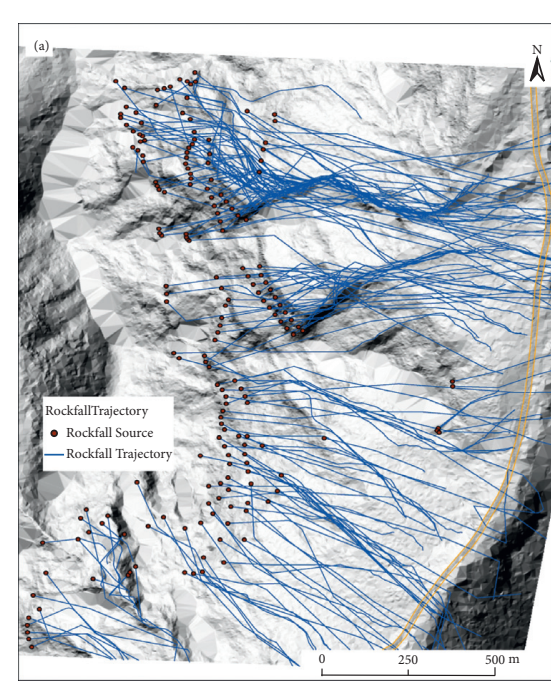

$\left(\mathrm{a}^{\prime}\right)$

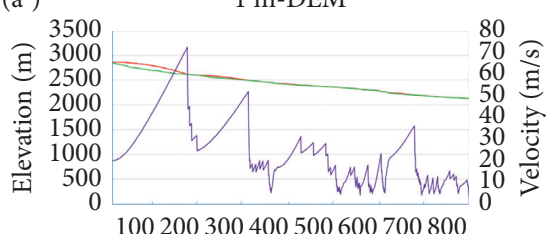

100200300400500600700800

Distance $(\mathrm{m})$

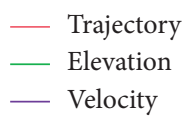

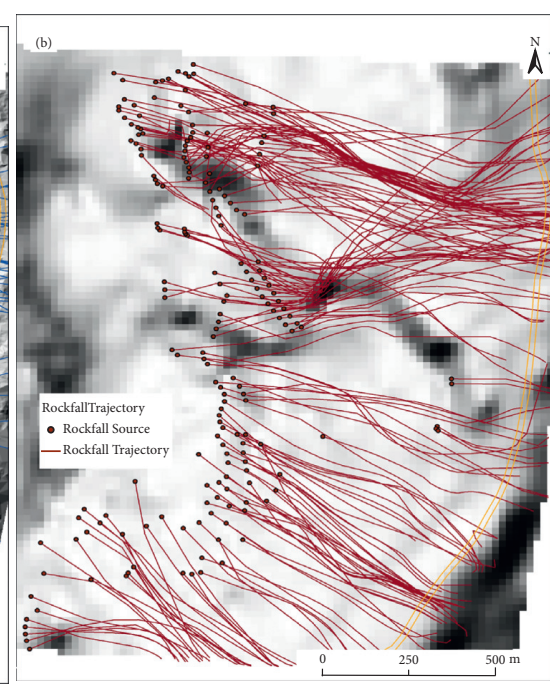

$\left(b^{\prime}\right)$

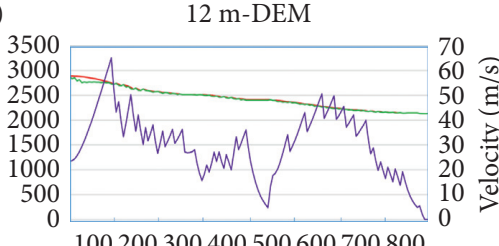

100200300400500600700800

Distance (m)

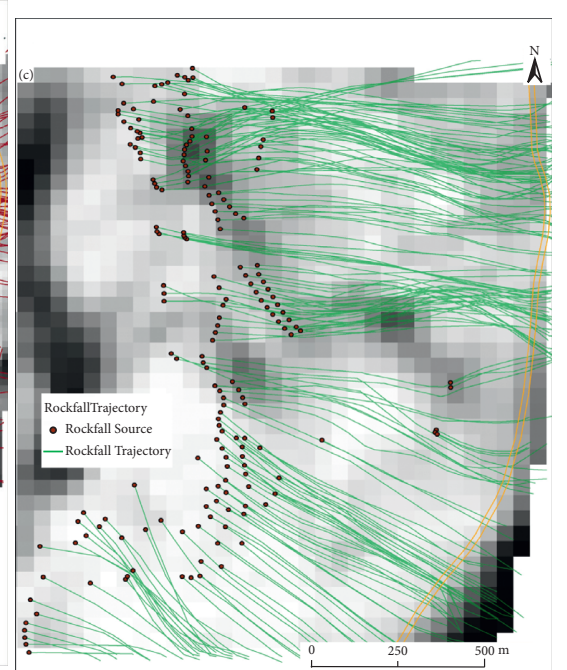

$\left(c^{\prime}\right)$

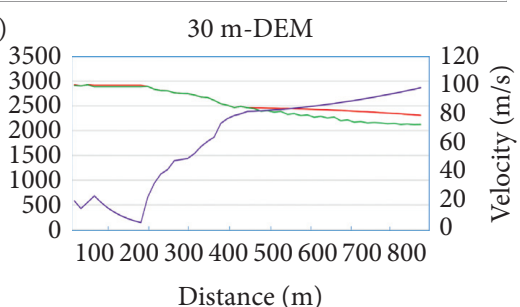

Distance $(\mathrm{m})$

FIGURE 7: (a) DEM with a $1 \mathrm{~m}$ resolution was used to simulate the path of falling rocks, (b) using DEM with $12.5 \mathrm{~m}$ resolution, and (c) using DEM with $30 \mathrm{~m}$ resolution. $\left(\mathrm{a}^{\prime}\right)$ The falling speed and distance of falling rocks at a $1 \mathrm{~m}$ resolution, $\left(\mathrm{b}^{\prime}\right)$ the falling speed and distance of falling rocks with a $12.5 \mathrm{~m}$ resolution, and $\left(\mathrm{c}^{\prime}\right)$ the falling speed and distance of falling rocks at a resolution of $30 \mathrm{~m}$.

speed is significantly less than that observed in the $30 \mathrm{~m}$ DEM simulation, and the falling rocks are airborne for significantly longer periods than seen using $30 \mathrm{~m}$ DEM.

This result shows that the accuracy of the terrain used for predicting the effects of simulated rockfall disasters is of significant importance. When DEM accuracy is increased to $1 \mathrm{~m}$, it can be seen from Figure 7(a) that the track of the falling rocks is significantly affected by changes in the topography. It can be seen from the figure that the falling rocks follow an obvious " $S$ " shaped path, and the speed of the fall is also significantly reduced. It is also evident when observing Figure $7(\mathrm{a})^{\prime}$ that the rocks are airborne for even longer periods, which is due to the influence of microgeomorphology. When the range of a dangerous rockfall is identified, it is, therefore, apparent that the path, speed, and height of the rockfall can be accurately simulated based on topographic and geomorphic data, which plays a very important role in the comprehensive assessment of geological safety along mountain roads.

\subsection{High-Precision Airborne LiDAR Data Is More Practical.} We used $5 * 5$ grids to calculate the slope and slope direction based on digital terrain analysis. Digital elevation models with resolutions of $30 \mathrm{~m}, 12.5 \mathrm{~m}$, and $1 \mathrm{~m}$ were used to carry out the risk assessment of the rockfall disaster.
Frequency, height, and energy raster layers were used to set the hazard class numbers. The comprehensive weight factor method was used to evaluate the risk level of the rockfall disaster. The spatial frequency distribution of the falling stones was obtained from the dynamic simulation of the paths of falling rocks, which was the most critical factor in rockfall evaluation. The weight was set at 0.5 .

At the same time, physical parameters such as rock mass can be estimated based on the scope of the material source area, and the gravitational potential energy contained in the material source area can be obtained indirectly. Greater amounts of potential energy are contained in larger rocks, with greater threats to nearby slopes, roads, and other forms of infrastructure. Therefore, the weight factor of rock energy was set at 0.3. Finally, the height of the rockfall source area is also an important factor. The higher the location of the rockfall source area, the greater the force generated by impact, and the more serious the threat to the slope and road, so the weight was set at 0.2. Using the above steps, different rockfall disasters were obtained and shown according to these categories. Images demonstrating the final evaluation are shown in Figure 8.

4.3. Disaster Simulation and Actual Analysis. As shown in Figure 8 , the collapse disaster image is a 0.5 -meter image taken after the earthquake disaster, which can clearly 

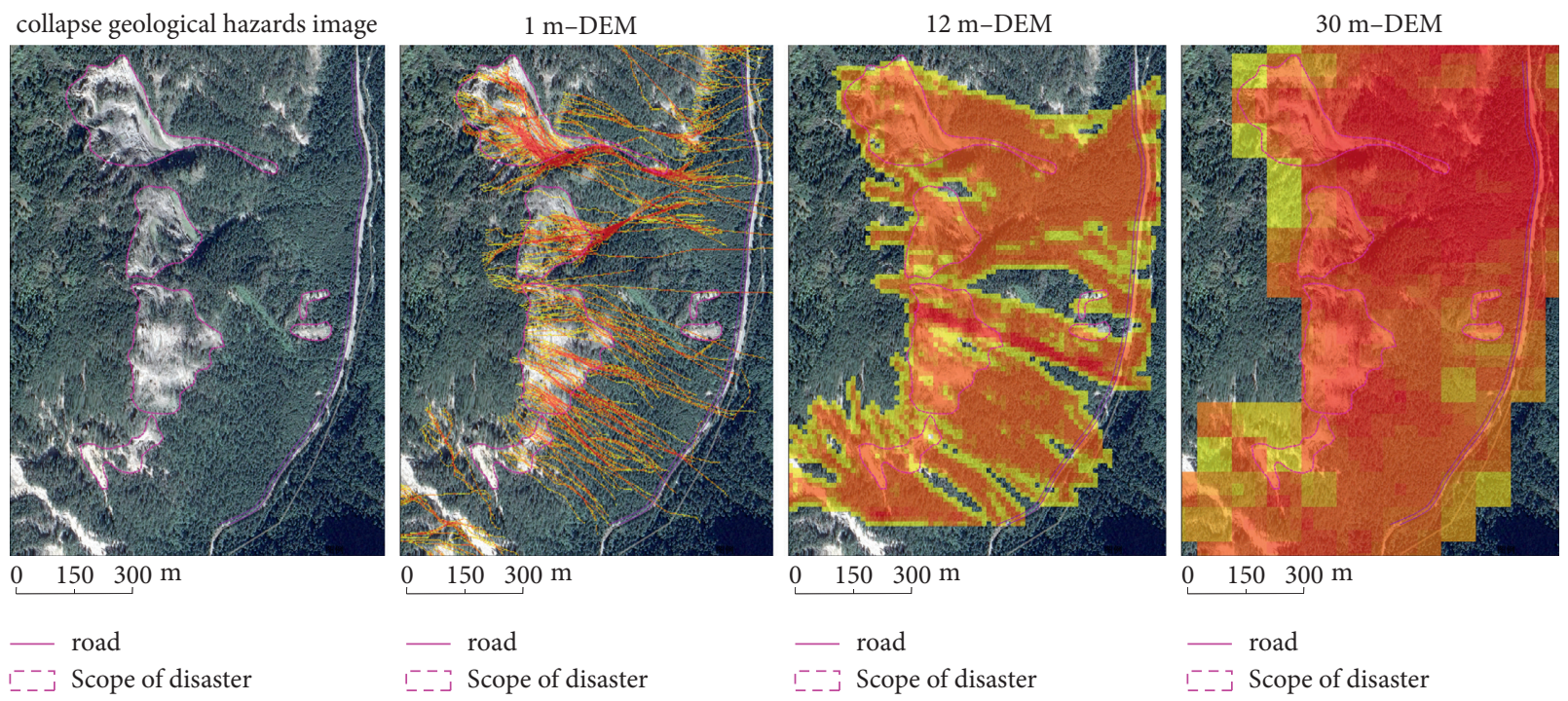

FIGURE 8: DEMs with different resolutions have different results in disaster evaluation along highways.

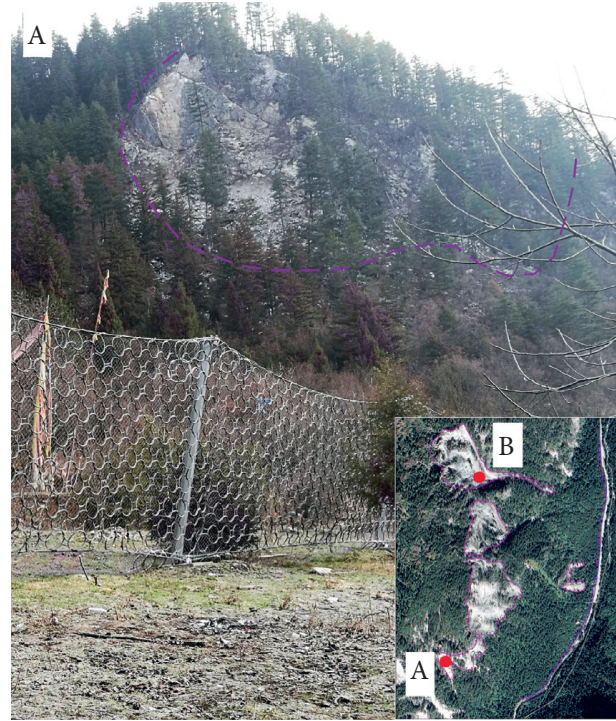

(a)

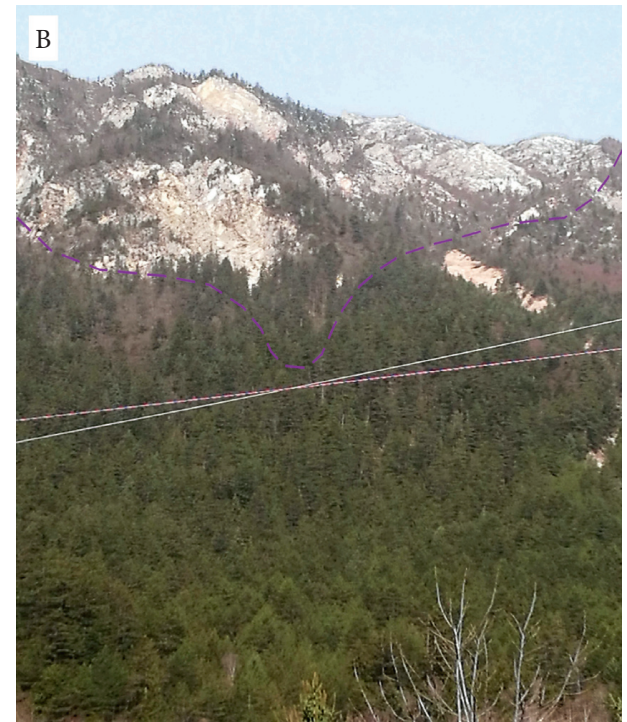

(b)

Figure 9: Field validation at points A and B shows that $1 \mathrm{~m}$ DEM data constructed by high-precision airborne LiDAR is more valuable for collapse risk analysis than DEM data of $12 \mathrm{~m}$ and $30 \mathrm{~m}$.

identify the threat range caused by the collapse disaster. We overlay the threat range and the DEM assessment results of $1 \mathrm{~m}, 12 \mathrm{~m}$, and $30 \mathrm{~m}$ resolution. Study found that $1 \mathrm{~m}$ resolution DEM evaluation of disaster threat range profile is more close to the actual situation, the simulation of the rolling stone path and vegetation breakage also conforms to the disaster situation, the scope and the threat of collapse disasters threat range Rolling Stones fit degree can reach more than $90 \%$, and the effect of 12 -meter DEM analysis is clearly "enlarge effect." However, the simulation effect of $30 \mathrm{~m}$ DEM basically "has no reference value." Therefore, high-precision DEM has high value in actual disaster analysis.
4.4. Field Validation. Through laboratory experiments, we have preliminarily concluded that high-precision remote sensing image has decisive value for the risk assessment of collapse disaster. In order to further verify the experimental conclusions, we adopted field investigations to verify them. Figure 9(a) shows Heye Village in Jiuzhaigou scenic spot. We matched the hazard assessment vector range of $1 \mathrm{~m}, 12 \mathrm{~m}$, and $30 \mathrm{~m}$ rolling stones with the longitude and latitude coordinates of the field. Through field inspection, most of the collapse disasters occurred within the range of $1 \mathrm{~m}$ DEM hazard assessment, as shown in the figure, and disaster prevention measures have been taken in area A. Similarly, at point $B$, the resolution assessment range of $1 \mathrm{~m}$ DEM is the 
closest to the actual situation, and the verification shows that it is the collapse disaster zone now. However, the predicted disaster range of 12 meters and 30 meters is obviously larger than the actual disaster range. It is found that the predicted area of 12 meters and 30 meters is covered by high vegetation currently, and no collapse disaster has occurred. Therefore, the above verification further proves that the collapse disaster prediction method constructed by high-precision airborne LiDAR is reliable and practical.

\section{Conclusions}

Rockfall is a natural phenomenon, but when it poses a threat to human life, the environment, roads, railways, or important support slopes, it becomes a hidden danger that must be considered. Scientific and reasonable assessment methods are, therefore, needed for comprehensive risk analysis. Traditional scientific evaluation methods are mostly based on optical remote sensing images and field investigation. Airborne laser radar technology has significant advantages over ground-based three-dimensional laser scanning technology or other forms of remote sensing technology as the laser pulse can obtain highly accurate data concerning topography through any vegetation that is present and can, therefore, be used to construct high fidelity topography data based on the digital terrain analysis technology from which the slope, slope direction, degree of concave and convex terrain, terrain roughness, and the openness of the terrain can be obtained. Factors such as optical remote sensing image data can, therefore, be used to accurately identify the potential sources of rockfalls when combined with field investigation to obtain the physical parameters of the rock in the study area. Finally, it can be used to accurately mitigate areas that are potentially prone to rockfall disaster and guide construction, to provide slope support, develop protective networks, construct retaining walls, and establish other systems for the prevention and control of geological disaster.

The early recognition and prediction of geological disaster is challenging, and although high-precision airborne LiDAR data can be used for the identification of possible sources of material for rockfall, risk assessment, and potential hazards, the cost of acquiring airborne LiDAR data can become extreme, so geological hazard investigations are often combined with oblique photography modeling to obtain high-precision digital surface modes for a study area, in which the model includes features concerning the terrain and the texture for clearer analysis of the potential threat from rock fracture and other important processes [34].

\section{Data Availability}

The high-precision airborne LiDAR data and DEM data used to support the findings of this study are included within the article.

\section{Conflicts of Interest}

The authors declare that they have no conflicts of interest.

\section{Acknowledgments}

The authors gratefully acknowledge the financial support of The National Key Research and Development Program of China (2018YFC1505202) and the National Natural Science Foundation of China (42072306).

\section{References}

[1] R. A. Kromer, D. J. Hutchinson, M. J. Lato, D. Gauthier, and T. Edwards, "Identifying rock slope failure precursors using LiDAR for transportation corridor hazard management," Engineering Geology, vol. 195, pp. 93-103, 2015.

[2] R. Mahalingam and M. J. Olsen, "Evaluation of the influence of source and spatial resolution of DEMs on derivative products used in landslide mapping," Geomatics, Natural Hazards and Risk, vol. 7, no. 6, pp. 1835-1855, 2015.

[3] E. Arnone, A. Francipane, A. Scarbaci, C. Puglisi, and L. V. Noto, "Effect of raster resolution and polygon-conversion algorithm on landslide susceptibility mapping," Environmental Modelling \& Software, vol. 84, pp. 467-481, 2016.

[4] W. Chen, X. Li, Y. Wang, G. Chen, and S. Liu, "Forested landslide detection using LiDAR data and the random forest algorithm: a case study of the Three Gorges, China," Remote Sensing of Environment, vol. 152, pp. 291-301, 2014.

[5] H. Kim, S. W. Lee, C.-Y. Yune, and G. Kim, "Volume estimation of small scale debris flows based on observations of topographic changes using airborne LiDAR DEMs," Journal of Mountain Science, vol. 11, no. 3, pp. 578-591, 2014.

[6] H. Lan, C. Derek Martin, and C. H. Lim, "RockFall analyst: a GIS extension for three-dimensional and spatially distributed rockfall hazard modeling," Computers \& Geosciences, vol. 33, no. 2, pp. 262-279, 2007.

[7] R. Copons and J. M. Vilaplana, "Rockfall susceptibility zoning at a large scale: from geomorphological inventory to preliminary land use planning," Engineering Geology, vol. 102, no. 3-4, pp. 142-151, 2008.

[8] P. M. Santi, C. P. Russell, J. D. Higgins, and J. I. Spriet, "Modification and statistical analysis of the Colorado rockfall hazard rating system," Engineering Geology, vol. 104, no. 1-2, pp. 55-65, 2009.

[9] V. Chiessi, M. D’Orefice, G. S. Mugnozza, V. Vitale, and C. Cannese, "Geological, geomechanical and geostatistical assessment of rockfall hazard in San Quirico Village (Abruzzo, Italy)," Geomorphology, vol. 119, no. 3-4, pp. 147-161, 2010.

[10] H. Lan, C. D. Martin, C. Zhou, and C. H. Lim, "Rockfall hazard analysis using LiDAR and spatial modeling," Geomorphology, vol. 118, no. 1-2, pp. 213-223, 2010.

[11] B. T. Pham, I. Prakash, and D. Tien Bui, "Spatial prediction of landslides using a hybrid machine learning approach based on Random Subspace and Classification and Regression Trees," Geomorphology, vol. 303, pp. 256-270, 2018.

[12] A. Erener, A. A. Sivas, A. S. Selcuk-Kestel, and H. S. Düzgün, "Analysis of training sample selection strategies for regression-based quantitative landslide susceptibility mapping methods," Computers \& Geosciences, vol. 104, pp. 62-74, 2017.

[13] G.-F. Lin, M.-J. Chang, Y.-C. Huang, and J.-Y. Ho, "Assessment of susceptibility to rainfall-induced landslides using improved self-organizing linear output map, support vector machine, and logistic regression," Engineering Geology, vol. 224, pp. 62-74, 2017.

[14] T. Bibi, K. Azahari Razak, A. Abdul Rahman, and A. Latif, "Spatio temporal detection and virtual mapping of landslide 
using high-resolution airborne laser altimetry (lidar) in densely vegetated areas of tropics," ISPRS - The International Archives of the Photogrammetry, Remote Sensing and Spatial Information Sciences, vol. XLII-4/W5, pp. 21-30, 2017.

[15] B. Kalantar, B. Pradhan, S. A. Naghibi, A. Motevalli, and S. Mansor, "Assessment of the effects of training data selection on the landslide susceptibility mapping: a comparison between support vector machine (SVM), logistic regression (LR) and artificial neural networks (ANN)," Geomatics, Natural Hazards and Risk, vol. 9, no. 1, pp. 49-69, 2017.

[16] G. C. Ohlmacher and J. C. Davis, "Using multiple logistic regression and GIS technology to predict landslide hazard in northeast Kansas, USA," Engineering Geology, vol. 69, no. 3-4, pp. 331-343, 2003.

[17] K.-T. Chang, S.-H. Chiang, and M.-L. Hsu, "Modeling typhoon- and earthquake-induced landslides in a mountainous watershed using logistic regression," Geomorphology, vol. 89, no. 3-4, pp. 335-347, 2007.

[18] A. Yalcin, S. Reis, A. C. Aydinoglu, and T. Yomralioglu, "A GIS-based comparative study of frequency ratio, analytical hierarchy process, bivariate statistics and logistics regression methods for landslide susceptibility mapping in Trabzon, NE Turkey," Catena, vol. 85, no. 3, pp. 274-287, 2011.

[19] I. Colkesen, E. K. Sahin, and T. Kavzoglu, "Susceptibility mapping of shallow landslides using kernel-based Gaussian process, support vector machines and logistic regression," Journal of African Earth Sciences, vol. 118, pp. 53-64, 2016.

[20] L. C. Razanamahandry, H. A. Andrianisa, H. Karoui, J. Podgorski, and H. Yacouba, "Prediction model for cyanide soil pollution in artisanal gold mining area by using logistic regression," Catena, vol. 162, pp. 40-50, 2018.

[21] Y. Xiong and R. Zuo, "GIS-based rare events logistic regression for mineral prospectivity mapping," Computers \& Geosciences, vol. 111, pp. 18-25, 2018.

[22] F. Guzzetti, A. Carrara, M. Cardinali, and P. Reichenbach, "Landslide hazard evaluation: a review of current techniques and their application in a multi-scale study, Central Italy," Geomorphology, vol. 31, no. 1, pp. 181-216, 1999.

[23] L. Otávio Aleotti Maia and R. Yahya Qassim, "Minimum cost safety stocks for frequent delivery manufacturing," International Journal of Production Economics, vol. 62, no. 3, pp. 233-236, 1999.

[24] K. Martinović et al., "Development of a landslide susceptibility assessment for a rail network," Engineering Geology, vol. 215, pp. 1-9, 2016.

[25] J. L. Florsheim, S. L. Ustin, Y. Tang et al., "Basin-scale and travertine dam-scale controls on fluvial travertine, Jiuzhaigou, southwestern China," Geomorphology, vol. 180-181, pp. 267280, 2013.

[26] S. Li, X. Hu, Y. Tang, C. Huang, and W. Xiao, "Changes in lacustrine environment due to anthropogenic activities over 240 years in Jiuzhaigou National Nature Reserve, southwest China," Quaternary International, vol. 349, pp. 367-375, 2014.

[27] Y. Kong, Z. Kong, Z. Liu, C. Wei, and G. An, "Substituting small hydropower for fuel: the practice of China and the sustainable development," Renewable and Sustainable Energy Reviews, vol. 65, pp. 978-991, 2016.

[28] X. Qiao, J. Du, S. Lugli et al., "Are climate warming and enhanced atmospheric deposition of sulfur and nitrogen threatening tufa landscapes in Jiuzhaigou National Nature Reserve, Sichuan, China?," The Science of the Total Environment, vol. 562, pp. 724-731, 2016.

[29] X. Qiao, J. Du, S. H. Kota, Q. Ying, W. Xiao, and Y. Tang, "Wet deposition of sulfur and nitrogen in Jiuzhaigou national nature reserve, sichuan, China during 2015-2016: challenges," Engineering Geology, vol. 241, pp. 25-32, 2018.

[30] D. Zhao, C. Qu, X. Shan, W. Gong, Y. Zhang, and G. Zhang, "InSAR and GPS derived coseismic deformation and fault model of the 2017 Ms7.0 Jiuzhaigou earthquake in the Northeast Bayanhar block," Tectonophysics, vol. 726, pp. 8699, 2018.

[31] Y. Chen, J. Hu, and F. Peng, "Seismological challenges in earthquake hazard reductions: reflections on the 2008 Wenchuan earthquake," Science Bulletin, vol. 63, no. 17, pp. 1159-1166, 2018.

[32] F. Huang, Z. Cao, S.-H. Jiang, C. Zhou, J. Huang, and Z. Guo, "Landslide susceptibility prediction based on a semi-supervised multiple-layer perceptron model," Landslides, vol. 17, no. 12, pp. 2919-2930, 2020.

[33] P. A. Burrough and R. A. McDonell, "Principles of Geographical Information Systems (Oxford University Press, New York), 190 ppPossible effects from regional emission reduction and local tourist activities," Environmental Pollution, vol. 233, pp. 267-277, 1998.

[34] L. Zhu, G. Wang, F. Huang, Y. Li, W. Chen, and H. Hong, "Landslide susceptibility prediction using sparse feature extraction and machine learning models based on GIS and remote sensing," IEEE Geoscience and Remote Sensing Letters, 2021. 